\title{
PERAN PENYULUH TERHADAP ADOPSI INOVASI PETERNAK AYAM KAMPUNG DI KECAMATAN TOMOHON BARAT
}

\author{
Viane Mangundap, A. K. Rintjap*, A. A. Sajow , J. Tumewu
}

Fakultas Peternakan Universitas Sam Ratulangi, 95115

\begin{abstract}
ABSTRAK
Penelitian ini dilaksanakan di Kecamatan Tomohon Barat pada bulan Desember 2019. Penelitian ini bertujuan untuk mengetahui peran penyuluh terhadap adopsi inovasi peternak dalam pengembangan ternak ayam kampung di Kecamatan Tomohon Barat. Penelitian ini berbentuk survei dengan menggunakan kuesioner. Penentuan sampel dilakukan secara Purposive Sampling dengan jumlah responden 30 peternak ayam kampung. Analisis data yang digunakan pada penelitian ini adalah analisis Chi-Square. Peran penyuluh diukur dengan menggunakan skala ordinal dari pertanyaan yang diajukan sedangkan adopsi inovasi diukur dengan skala ordinal tingkat pengetahuan, sikap dan keterampilan peternak ayam kampung. Pengetahuan dibagi menjadi beberapa kategori yaitu pengetahuan tinggi, sedang dan rendah, sikap kategorinya menerima inovasi, cukup menerima inovasi dan menolak inovasi, keterampilan kategorinya terampil, cukup terampil dan tidak terampil. Hasil penelitian dengan menggunakan analisis Chi-Square menunjukkan bahwa peran penyuluh memiliki hubungan yang signifikan dengan sikap peternak ayam kampung sedangkan disisi lain peran penyuluh tidak memiliki hubungan yang signifikan dengan pengetahuan dan keterampilan peternak ayam kampung.
\end{abstract}

Kata kunci : Peran Penyuluh, Adopsi Inovasi, Analisis Chi-Square.

*Korespondensi (Corresponding author): Email: annekerintjap@unsrat.ac.id
ABSTRACT

THE ROLE OF EXTENSION TO THE ADOPTION OF FARMERS INNOVATION IN THE DEVELOPMENT OF WEST TOMOHON DISTRICT TOMOHON CITY. Study was conducted on December 2019 to evaluate the role extension in the adoption of smallholder innovation in development of native chicken at West Tomohon District. This research was a survey using questionnaires. Samples were determind by purposive sampling method involving 30 smallholder of local native chicken. Chi square method was used to analyze the data. The role of extension was meansured by ordinal scale for questions given to breeders and the adoption of innovation was measured by ordinal scale of the level of knowledge, attitudes and skills of native chicken farmers. Knowledge was divided into several categories, namely high, medium and low knowledge, the attitude of the category accepts innovation, it is enough to accept innovation and reject innovation, the skill of the category was skilled, sufficiently skilled and unskilled. The results of the study used Chi-Square analysis showed that the role of extension workers had a significant relationship with the attitudes of native chicken farmers while on the other hand the role of extension workers did not not have a significant relationship with the knowledge and skills of native chicken farmers. 
Key words: The Role of Extension, Innovation Adoption, Chi-Square Analysis.

\section{PENDAHULUAN}

Ayam kampung merupakan salah satu komoditi peternakan yang dapat menunjang pembangunan di sektor peternakan sebagai sumber pendapatan keluarga jika dikelola secara professional (Rawung et al., 2017). Menurut Rintjap et al., (2016), menyatakan bahwa penyuluh memiliki peran penting dalam pengembangan peternakan dan peningkatan proses adopsi teknologi peternakan kepada para peternak. keberhasilan proses dalam adopsi teknologi sangat ditentukan oleh model penyuluhan yang sesuai dengan kebutuhan peternak, yaitu ketepatan materi, metode dan media yang digunakan (Rintjap et al., 2016). Menurut Anwas (2013), untuk meningkatkan kompetensi banyak upaya yang dapat dilakukan diantaranya melalui peningkatan pendidikan, pelatihan, diskusi antar penyuluh, penyediaan sarana dan prasarana penyuluhan yang diasumsikan memiliki pengaruh yang signifikan terhadap peningkatan kompetensi penyuluh pertanian. Keputusan inovasi merupakan suatu tipe pengambilan keputusan yang khas karena mereka harus memilih alternatif baru atau inovasi dan meninggalkan teknologi lama. (Efendy dan Hutapea, 2010). Penyuluhan sangat diperlukan eksistensinya untuk mendukung kehidupan umat manusia (Amanah, 2007). Menurut Rogers dalam Indraningsih (2011), menyatakan bahwa sifat suatu inovasi dan ketidakpastian berhubungan dengan sifat tersebut yang Menimbulkan pertanyaan apakah proses penyuluhan telah berlangsung dengan efektif?. Untuk memanfaatkan teknologi baru petani memerlukan modal yang besar, dan inovasi yang diterapkan tidak rumit dan mudah untuk dimengerti. Menurut Lombogia et al. (2017), menyatakan bahwa hasil dari penyuluhan tidak dapat diketahui dalam waktu yang singkat terlebih lagi jika tujuan utama suatu program penyuluhan adalah terjadinya adopsi suatu inovasi merupakan aspek khusus dari pengambilan keputusan inovasi. Hal ini membutuhkan kinerja penyuluh pertanian yang terintegrasi pada pelaksanaan tugas pokok dan fungsi penyuluh pertanian dalam merencanakan, mengorganisasikan dan mengevaluasi program penyuluhan pertanian (Rahmawati, 2016). Penyuluh adalah kunci dari keberhasilan program pemerintah di lapangan dalam rangka pembangunan bidang pertanian, mentransfer informasi serta inovasi baru kepada peternak (Putra et al., 2012)

\section{Kegiatan Penyuluhan yang} dilaksanakan di Kelurahan Woloan Satu, Woloan Satu Utara, Woloan Dua, Woloan 
Tiga Kecamatan Tomohon Barat diadakan setiap 3 bulan sekali sesuai program pemerintah. Teknologi yang dianjurkan penyuluh berupa mesin tetas ternyata belum mampu diadopsi oleh peternak.

Tujuan Penelitian ini adalah untuk menganalisis peran penyuluh terhadap pengetahuan, sikap dan keterampilan peternak dalam pengembangan ternak ayam kampung di Kelurahan Woloan Satu, Woloan Satu Utara, Woloan Dua, Woloan Tiga Kecamatan Tomohon Barat.

\section{METODE PENELITIAN}

\section{Lokasi dan Waktu Penelitian}

Penelitian ini dilaksanakan di Kelurahan Woloan Satu, Woloan Satu Utara, Woloan Dua, Woloan Tiga Kecamatan Tomohon Barat, Kota Tomohon.Dilaksanakan pada Bulan Desember 2019.

\section{Jenis dan Sumber Data}

Penelitian ini berbentuk survei jenis penelitian kualitatif yang bersifat menganalisis bagaimana peran penyuluh terhadap adopsi inovasi peternak.

Sumber data yang digunakan dalam penelitian ini adalah Data primer diperoleh dari hasil observasi dan wawancara dengan menggunakan kuesioner kepada peternak ayam kampung yang ada di Kecamatan Tomohon Barat.Data sekunder diperoleh dari Dinas Pertanian dan Peternakan Kecamatan Tomohon Barat dan Balai Penyuluhan Pertanian Perikanan dan
Kehutanan (BP3K) kecamatan Tomohon Barat.

\section{Metode Penentuan Sampel}

Lokasi penelitian diambil secara purposive sampling dengan pertimbangan terdapat peternak ayam kampung dan populasi ternak ayam kampung terbanyak. Populasi adalah peternak ayam kampung yang berada di Kecamatan Tomohon Barat. Penentuan sampel dilakukan secara Purposive Sampling, dengan pertimbangan peternak yang memiliki ternak minimal 30 ekor ayam dewasa, beternak minimal 2 tahun dan pernah mengikuti kegiatan penyuluhan sehingga diperoleh jumlah responden sebanyak 30 peternak ayam kampung.

\section{Analisis Data}

Analisis data yang digunakan dalam penelitian ini adalah metode deskriptif, yaitu suatu metode atau cara menganalisis dan menguraikan data penelitian yang ada dan dikaitkan dengan teori-teori yang ada. Untuk menguji hubungan variabel peran penyuluh dengan adopsi inovasi, maka variabel peran penyuluh diukur menggunakan skala ordinal dengan kategori banyak berperan, cukup berperan dan kurang berperan. Adopsi inovasi diukur dengan pendekatan pengetahuan, sikap dan keterampilan peternak menggunakan skala ordinal. Selanjutnya dengan menggunakan skoring terhadap jawaban responden terhadap 
pertanyaan ataupun pernyataan yang diberikan diperoleh beberapa kategori dari ketiga variabel tersebut. Variabel pengetahuan terdiri atas pengetahuan tinggi, sedang dan rendah. Variabel sikap terdiri atas menerima, cukup menerima dan menolak inovasi. Variabel keterampilan terdiri atas kategori terampil, cukup terampil dan tidak terampil . Analisis yang digunakan yaitu analisis Chi Square $\left(\chi^{2}\right)$ adalah pengujian hipotesis mengenai perbandingan antara frekuensi observasi atau yang benar benar terjadi $\left(O_{i}\right)$ dengan frekuensi harapan atau ekspektasi $\left(e_{i}\right)$ yang didasarkan atas hipotesis tertentu. Frekuensi observasi nilainya didapat dari hasil percobaan, sedangkan frekuensi harapan nilainya dapat dihitung secara teoritis.

Rumus: $\quad \chi^{2}=\sum_{1}^{\mathrm{n}} \frac{\left(O_{i}-e_{i}\right)^{2}}{e_{i}}$

Dimana :
$\mathrm{N}=30$

$\chi^{2}=$ Chi-Square

$O_{i}=$ Frekuensi data yang didapat dari hasil observasi

$\left(e_{i}\right)=$ Frekuensi data harapan atau yang diharapkan.

\section{HASIL DAN PEMBAHASAN}

\section{Peran Penyuluh}

Peran penyuluh diukur dengan menghitung hasil jawaban dari peternak berdasarkan pertanyaan dan adopsi inovasi diukur dengan melihat tingkat pengetahuan, sikap dan keterampilan peternak ayam kampung yang dihasilkan oleh peran penyuluh.

\section{Pengetahuan Peternak}

Soekartawi dalam Lestari et al., (2009), menyatakan bahwa peternak yang berpendidikan tinggi relatif cepat melaksanakan adopsi inovasi.

Tabel 1. Peran Penyuluh.

\begin{tabular}{lccc}
\hline & Peran Penyuluh & Jumlah (orang) & Persentase (\%) \\
\hline Banyak & 16 & 53.3 \\
Cukup & 9 & 30.0 \\
Kurang & \multirow{2}{*}{ Jumlah } & 5 & 16.6 \\
& & 30 & 100 \\
\hline
\end{tabular}

Tabel 2. Pengetahuan Peternak.

\begin{tabular}{cccc}
\hline No & \multicolumn{1}{c}{ Pengetahuan } & Jumlah (orang) & Persentase $(\%)$ \\
\hline 1 & Rendah & 15 & 50.0 \\
2 & Sedang & 11 & 36.7 \\
3 & Tinggi & 4 & 13.3 \\
& & 30 & 100 \\
\hline
\end{tabular}


Tabel 3. Sikap Peternak.

\begin{tabular}{cccc}
\hline No & Sikap & Jumlah (orang) & Persentase $(\%)$ \\
\hline 1 & Menerima inovasi & 20 & 66.7 \\
2 & Cukup menerima & 9 & 30.0 \\
3 & Menolak inovasi & 1 & 3.3 \\
& Jumlah & 30 & 100 \\
\hline
\end{tabular}

Tabel 4. Keterampilan Peternak.

\begin{tabular}{clcc}
\hline No & \multicolumn{1}{c}{ Keterampilan } & Jumlah (orang) & Persentase $(\%)$ \\
\hline 1 & Terampil & 20 & 66.7 \\
2 & Cukup terampil & 8 & 26.7 \\
3 & Terampil & 2 & 6.3 \\
& $\quad$ Jumlah & 30 & 100 \\
\hline
\end{tabular}

\section{Sikap Peternak}

Aiken dalam Dwijayanti (2003), menyatakan bahwa sikap adalah predisposisi atau kecenderungan yang dipelajari dari seorang individu untuk merespon secara positif atau negatif dengan intensitas yang modera.

\section{Keterampilan Peternak}

Keterampilan dalam hal ini sangat diperlukan agar dapat dilihat cara bekerja peternak dalam segi pemeliharaan ternak ayam kampung setelah adanya penyuluhan.

\section{Nilai Kontingensi Peran Penyuluh}

Penyuluh yang berhasil adalah penyuluh yang dapat merancang dan melaksanakan suatu program pembelajaran, dimana materi dan metodenya sesuai dengan kondisi karakteristik petani (Sapar et al., 2012)

Tabel 5. Nilai Kotingensi Peran Penyuluh dengan Pengetahuan Peternak Ayam Kampung.

\begin{tabular}{|c|c|c|c|c|c|c|c|}
\hline \multicolumn{8}{|c|}{ Tabel Kontingensi Pengetahuan } \\
\hline \multirow{2}{*}{$\begin{array}{c}\text { Peran } \\
\text { Penyuluh }\end{array}$} & \multicolumn{2}{|c|}{ Tinggi } & \multicolumn{2}{|c|}{ Sedang } & \multicolumn{2}{|c|}{ Rendah } & \multirow{2}{*}{$\begin{array}{l}\text { Total } \\
\text { Baris }\end{array}$} \\
\hline & $\left(o_{i}\right)$ & $\left(e_{i}\right)$ & $\left(o_{i}\right)$ & $\left(e_{i}\right)$ & $\left(o_{i}\right)$ & $\left(e_{i}\right)$ & \\
\hline \multirow[t]{2}{*}{ Banyak } & & 10.5 & & 7.7 & & 1.4 & \\
\hline & 12 & & 7 & & 2 & & 21 \\
\hline \multirow[t]{2}{*}{ Cukup } & & 3.5 & & 2.5 & & 0.4 & \\
\hline & 3 & & 3 & & 1 & & 7 \\
\hline \multirow{2}{*}{ Kurang } & & 1.0 & & 0.7 & & 0.2 & \\
\hline & 0 & & 1 & & 1 & & 2 \\
\hline Total & & & & & & & Total Observasi \\
\hline Kolom & 15 & & 11 & & 4 & & $=30$ \\
\hline
\end{tabular}


Tabel 6. Uji Analisis Chi-Square Peran Penyuluh dengan Pengetahuan.

\begin{tabular}{lccccc}
\hline $\begin{array}{l}\text { Peran Penyuluh / } \\
\text { Pengetahuan }\end{array}$ & $\left(o_{i}\right)$ & $\left(e_{i}\right)$ & $\left(o_{i}-e_{i}\right)$ & $\left(o_{i}-e_{i}\right)^{2}$ & $\left(o_{i}-e_{i}\right)^{2 /} e_{i}$ \\
\hline BB/Pengetahuan Tinggi & 12 & 10.5 & 1.5 & 2.25 & 0.214 \\
BB/Pengetahuan Sedang & 7 & 7.7 & -0.7 & 0.49 & 0.063 \\
BB/Pengetahuan Rendah & 2 & 1.4 & 0.6 & 0.36 & 0.257 \\
CB/Pengetahuan Tinggi & 3 & 3.5 & -0.5 & 0.25 & 0.071 \\
CB/ Pengetahuan Sedang & 3 & 2.5 & 0.5 & 0.25 & 0.100 \\
CB/ Pengetahuan Rendah & 1 & 0.4 & 0.6 & 0.36 & 0.900 \\
KB/ Pengetahuan Tinggi & 0 & 1 & -1 & 1 & 1.000 \\
KB/ Pengetahuan Sedang & 1 & 0.7 & 0.3 & 0.09 & 0.123 \\
KB/ Pengetahuan Rendah & 1 & 0.2 & 0.8 & 0.64 & 3.200 \\
\hline \multicolumn{1}{c}{ Jumlah } & 30 & 30 & & & 5.933 \\
\hline
\end{tabular}

Keterangan :

(BB) : penyuluh banyak berperan

(CB) : penyuluh cukup berperan

$(\mathrm{KB})$ : penyuluh kurang berperan

Untuk mengetahui hubungan peran penyuluh dengan pengetahuan peternak maka akan dilakukan pengujian kebebasan variabel dengan taraf uji $5 \%$

Ukuran tabel kontingensi di atas $=3 \times 3$ baris dan 3 kolom) $\mathrm{db}=(3-1)(3-1)=2 \times 2=4$

nilai Tabel $x^{2} \mathrm{db}=4 ; \alpha=0.05 \rightarrow x^{2}$ tabel

$=9.488$

$x^{2}$ hitung $=5.933$

$x^{2}$ tabel $=9.488$

$x^{2}$ hitung lebih kecil dari $x^{2}$ tabel jadi $H_{0}$ diterima artinya pengaruh peran penyuluh dengan pengetahuan peternak tidak signifikan 
Tabel 7. Nilai Kontigensi Peran Penyuluh dengan Sikap Peternak Ayam kampung.

\begin{tabular}{|c|c|c|c|c|c|c|c|}
\hline \multicolumn{8}{|c|}{ Tabel Kontingensi Sikap } \\
\hline \multirow{2}{*}{$\begin{array}{c}\text { Peran } \\
\text { Penyuluh }\end{array}$} & \multicolumn{2}{|c|}{$\begin{array}{l}\text { Menerima } \\
\text { Inovasi }\end{array}$} & \multicolumn{2}{|c|}{$\begin{array}{l}\text { Cukup } \\
\text { Menerima }\end{array}$} & \multicolumn{2}{|c|}{$\begin{array}{c}\text { Menolak } \\
\text { Inovasi }\end{array}$} & \multirow{2}{*}{ Total Baris } \\
\hline & $\left(o_{i}\right)$ & $\left(e_{i}\right)$ & $\left(o_{i}\right)$ & $\left(e_{i}\right)$ & $\left(o_{i}\right)$ & $\left(e_{i}\right)$ & \\
\hline \multirow{2}{*}{ Banyak } & & 13.3 & & 6 & & 0.6 & \\
\hline & 14 & & 6 & & 0 & & 20 \\
\hline \multirow{2}{*}{ Cukup } & & 4.7 & & 4.7 & & 0.23 & \\
\hline & 4 & & 2 & & 1 & & 7 \\
\hline \multirow{2}{*}{ Kurang } & & 2 & & 0.9 & & 0.01 & \\
\hline & 2 & & 1 & & 0 & & 3 \\
\hline $\begin{array}{l}\text { Total } \\
\text { Kolom }\end{array}$ & 20 & & 9 & & 1 & & $\begin{array}{c}\text { Total } \\
\text { Observasi }=30\end{array}$ \\
\hline
\end{tabular}

Tabel 8. Uji Analisis Chi-Square Peran Penyuluh dengan Sikap.

\begin{tabular}{lccccc}
\hline $\begin{array}{l}\text { Peran Penyuluh / } \\
\text { Sikap }\end{array}$ & $\left(o_{i}\right)$ & $\left(e_{i}\right)$ & $\left(o_{i}-e_{i}\right)$ & $\left(o_{i}-e_{i}\right)^{2}$ & $\left(o_{i}-e_{i}\right)^{2 /} e_{i}$ \\
\hline BB/Menerima Inovasi & 14 & 13.3 & 0.7 & 0.49 & 0.036 \\
BB/Cukup Menerima & 6 & 6 & 0 & 0.0 & 0.000 \\
BB/Menolak Inovasi & 0 & 0.6 & -0.6 & 0.36 & 0.600 \\
CB/ Menerima Inovasi & 4 & 4.7 & -0.7 & 0.49 & 0.104 \\
CB/ Cukup Menerima & 2 & 4.7 & -0.1 & 0.01 & 0.004 \\
CB/ Menolak Inovasi & 1 & 0.23 & 0.77 & 0.59 & 2.565 \\
KB/ Menerima Inovasi & 2 & 2 & 0 & 0 & 0.000 \\
KB/ Cukup Menerima & 1 & 0.9 & 0.1 & 0.01 & 0.110 \\
KB/ Menolak Inovasi & 0 & 0.01 & 0.9 & 0.81 & 8.100 \\
\hline \multicolumn{1}{c}{ Jumlah } & 30 & 30 & & & 11.519 \\
\hline
\end{tabular}

Keterangan :

(BB) : penyuluh banyak berperan

(CB) : penyuluh cukup berperan

$(\mathrm{KB})$ : penyuluh kurang berperan

Untuk mengetahui hubungan peran penyuluh dengan pengetahuan peternak maka akan dilakukan pengujian kebebasan variabel dengan taraf uji 5\%

Ukuran tabel kontingensi di atas $=3 \times 3(3$ baris dan 3 kolom) $\mathrm{db}=(3-1)(3-1)=2 \times 2=4$

nilai Tabel $x^{2} \mathrm{db}=4 ; \alpha=0.05 \rightarrow x^{2}$ tabel $=9.488$

$x^{2}$ hitung $=11.519$

$x^{2}$ tabel $=9.488$

$x^{2}$ hitung lebih besar dari $x^{2}$ tabel jadi $H_{l}$ diterima artinya pengaruh peran penyuluh dengan sikap peternak signifikan. 
Tabel 9. Nilai Kontingensi Peran Penyuluh dengan Keterampilan Peternak Ayam kampung.

Tabel Kontingensi Keterampilan

\begin{tabular}{|c|c|c|c|c|c|c|c|}
\hline \multirow{2}{*}{$\begin{array}{c}\text { Peran } \\
\text { Penyuluh }\end{array}$} & \multicolumn{2}{|c|}{ Terampil } & \multicolumn{2}{|c|}{$\begin{array}{l}\text { Cukup } \\
\text { Terampil }\end{array}$} & \multicolumn{2}{|c|}{$\begin{array}{c}\text { Tidak } \\
\text { Terampil }\end{array}$} & \multirow{2}{*}{ Total Baris } \\
\hline & $\left(o_{i}\right)$ & $\left(e_{i}\right)$ & $\left(o_{i}\right)$ & $\left(e_{i}\right)$ & $\left(o_{i}\right)$ & $\left(e_{i}\right)$ & \\
\hline \multirow{2}{*}{ Banyak } & & 10.6 & & 6.6 & & 2.6 & \\
\hline & 11 & & 4 & & 1 & & 16 \\
\hline \multirow{2}{*}{ Cukup } & & 4.2 & & 2.6 & & 1.0 & \\
\hline & 6 & & 3 & & 1 & & 10 \\
\hline \multirow{2}{*}{ Kurang } & & 1.0 & & 0.6 & & 0.2 & \\
\hline & 3 & & 1 & & 0 & & 4 \\
\hline $\begin{array}{l}\text { Total } \\
\text { Kolom }\end{array}$ & 20 & & 8 & & 2 & & $\begin{array}{c}\text { Total } \\
\text { Observasi }=30\end{array}$ \\
\hline
\end{tabular}

Tabel 10. Uji Analisis Chi-Square Peran Penyuluh dengan Keterampilan.

\begin{tabular}{lccccc}
\hline $\begin{array}{l}\text { Peran Penyuluh / } \\
\text { Sikap }\end{array}$ & $\left(o_{i}\right)$ & $\left(e_{i}\right)$ & $\left(o_{i}-e_{i}\right)$ & $\left(o_{i}-e_{i}\right)^{2}$ & $\left(o_{i}-e_{i}\right)^{2 /} e_{i}$ \\
\hline BB/Terampil & 11 & 10.6 & 0.4 & 0.16 & 0.015 \\
BB/Cukup Terampil & 4 & 6.6 & -2.5 & 6.25 & 0.950 \\
BB/Tidak Terampil & 1 & 2.6 & -1.6 & 2.56 & 1.024 \\
CB/ Terampil & 6 & 4.2 & 1.8 & 3.24 & 0.771 \\
CB/ Cukup Terampil & 3 & 2.6 & 0.4 & 0.16 & 0.060 \\
CB/ Tidak Terampil & 1 & 1.0 & 0.0 & 0.00 & 0.000 \\
KB/ Terampil & 3 & 1.0 & 2.0 & 1.00 & 1.000 \\
KB/ Cukup Terampil & 1 & 0.6 & 0.4 & 0.16 & 0.260 \\
KB/ Tidak Terampil & 0 & 0.2 & -0.2 & 0.04 & 0.200 \\
\hline \multicolumn{1}{c}{ Jumlah } & 30 & 30 & & & 4.280 \\
\hline
\end{tabular}

Keterangan :

(BB) : penyuluh banyak berperan

(CB) : penyuluh cukup berperan

$(\mathrm{KB})$ : penyuluh kurang berperan

Untuk mengetahui hubungan peran penyuluh dengan pengetahuan peternak maka akan dilakukan pengujian kebebasan variabel dengan taraf uji 5\%

Ukuran tabel kontingensi di atas $=3 \times 3(3$ baris dan 3 kolom) $\mathrm{db}=(3-1)(3-1)=2 \times 2=4$

nilai Tabel $x^{2} \mathrm{db}=4 ; \alpha=0.05 \rightarrow x^{2}$ tabel $=9.488$

$x^{2}$ hitung $=4.280$

$x^{2}$ tabel $=9.488$

$x^{2}$ hitung lebih kecil dari $x^{2}$ tabel jadi $H_{1}$ diterima artinya pengaruh peran penyuluh dengan keterampilan peternak tidak signifikan. 
Mardikanto dalam Hanafi (2011), menyatakan bahwa jumlah kepemilikan ternak berpengaruh terhadap tingkat pendapatan. Peternak dengan tingkat pendapatan semakin tinggi biasanya akan semakin cepat mengadopsi inovasi. Menurut Rintjap et al. (2017) bahwa penyuluhan yang dilaksanakan dikatakan meningkat apabila terjadi perubahan pengetahuan, sikap dan keterampilan dari peternak dalam mengadopsi teknologi untuk meningkatkan cara beternak agar lebih baik. Berdasarkan hasil penelitian Far (2014), yang menyatakan bahwa sebagai sistem pendidikan non formal, penyuluh pertanian merupakan suatu usaha untuk menimbulkan perubahan perilaku peternak ayam kampung seperti perubahan pengetahuan, perubahan keterampilan teknis yang lebih baik serta perubahan sikap atau sifat untuk lebih produktif sehinggah para peternak ayam kampung dapat merubah perilaku dalam meningkatkan usaha ternak ayam kampung dan cara berusaha agar lebih menguntungkan.

\section{KESIMPULAN}

Berdasarkan hasil penelitian dapat disimpulkan bahwa hubungan peran penyuluh dengan pengetahuan dan keterampilan peternak tidak signifikan dan hubungan peran penyuluh dengan sikap peternak signifikan.

\section{DAFTAR PUSTAKA}

Amanah, S. 2007. Makna penyuluhan dan transformasi perilaku manusia. Jurnal Penyuluhan 3(1): 63-67.

Anwas O. M. 2013. Pengaruh pendidikan formal, pelatihan, dan intensitas pertemuan terhadap kompetensi penyuluh pertanian. Jurnal Pendidikan dan Kebudayaan. 19(1): 50-62.

Dwijayanti, 2003. Motivasi Peternak dalam Kegiatan Berusaha Ternak Domba di Desa Saganten Cianjur, Jawa Barat. Skripsi. Institut Pertanian Bogor, Bogor.

Efendy, J., Y. Hutapea. 2010. Analisis adopsi inovasi teknologi pertanian berbasis padi di Sumatera Selatan dalam perspektif komunikasi. Jurnal Pengkajian dan Pengembangan Teknologi Pertanian. 13(2):125-129.

Far, R. A. F. 2014. Respon petani terhadap penerapan metode penyuluhan pertanian di Kota Ambon Provinsi Maluku. Jurnal Budidaya Pertanian 10(10):48-51.

Hanafi, H. 2011. Pendekatan Model Komunikasi, Partisipasi Kelompok dalam Adopsi Inovasi Agribisnis Ternak Kambing PE di Girikerto Sleman, Daerah Istimewa Yogyakarta. Skripsi. Institut Pertanian, Bogor.

Indraningsih, K. S. 2011. Pengaruh penyuluhan terhadap keputusan petani dalam adopsi inovasi teknologi usaha tani terpadu. Jurnal Agro Ekonomi 29(1):4-7.

Lestari, S. Hadi, N. Indris. 2009. Tingkat adopsi inovasi peternak dalam beternak ayam broiler di Kecamatan Bajubang Kabupaten Batang Hari. Jurnal Penyuluhan 12(1):17-20. 
Lombogia S.O.B., I. D. R, Lumenta, Y. L. Tulung. 2017. Potensi pengembangan usaha ternak ayam buras di Kabupaten Minahasa. Prosiding, Seminar nasional pengembangan unggas lokal di Indonesia. Universitas Sam Ratulangi, Manado, 30 Agustus 2017. P. 122-124.

Putra, A. W., S. Hariadi, Harsyono 2012. Pengaruh peran penyuluh dan kearifan lokal terhadap adopsi inovasi padi sawah di Kecamatan Montasik Kabupaten Aceh Besar. Jurnal Penyuluhan dan Komunikasi 1(1):89-91.

Rahmawati, R. I. 2016. Peran penyuluh pertanian dalam memberdayakan peternak ayam petelur di Kabupaten Jember. Jurnal Penyuluhan 12(3):184-185.

Rawung, V. R. W. dan W. Utiah. 2017. Aplikasi mesin tetas pada ayam kampung, IBM kelompok peternak ayam kampung di Desa Tenga. Prosiding, Seminar nasional pengembangan unggas lokal di Indonesia. Universitas Sam Ratulangi, Sulawesi Utara, 30 Agustus 2017. P. 109-110.
Rintjap, A. K., J. Tumewu, dan H. O. Gijoh. 2016. Pemanfaatan media elektronik dalam proses penyuluhan pada kelompok ayam buras wanita kaum ibu di Kelurahan Kinali Kabupaten Minahasa. Prosiding, Seminar nasional pengembangan pedesaan berkelanjutan berbasis peternakan di Indonesia. Universitas Sam Ratulangi, Manado, Sulawesi Utara, 11-12 Agustus 2016. P. 110112.

Rintjap, A. K., J. Lainawa dan T. Lumy. 2017. Penyuluhan BP3K terhadap perkembangan usaha pemeliharaan ayam kampung di Kecamatan Pineleng Kabupaten Minahasa. Prosiding, Seminar nasional pengembangan pedesaan berkelanjutan berbasis peternakan di Indonesia. Universitas Sam Ratulangi, Manado, 23 Maret 2018. P. 108-110.

Sapar, A. Jahi, P. Asngari, Amiruddin dan I.G Putu Purnaba. 2012. Kinerja penyuluh pertanian dan dampaknya pada kelompok petani kakao di Empat Wilayah Sulawesi Selatan. Jurnal Penyuluhan 8(1):31-33. 